\title{
MicroRNA-182-5p targets a network of genes involved in DNA repair
}

\author{
KEERTHANA KRISHNAN, ${ }^{1}$ ANITA L. STEPTOE ${ }^{1}$ HILARY C. MARTIN, ${ }^{1,5}$ SHIVANGI WANI, ${ }^{1}$ KATIA NONES, ${ }^{1}$ \\ NIC WADDELL, ${ }^{1}$ MYTHILY MARIASEGARAM, ${ }^{2}$ PETER T. SIMPSON, ${ }^{2}$ SUNIL R. LAKHANI, ${ }^{2}$ BRIAN GABRIELLI, ${ }^{3}$ \\ ALEXANDER VLASSOV,${ }^{4}$ NICOLE CLOONAN, ${ }^{1,6}$ and SEAN M. GRIMMOND ${ }^{1,6}$ \\ ${ }^{1}$ Queensland Centre for Medical Genomics, Institute for Molecular Bioscience, The University of Queensland, St Lucia, QLD, Australia 4072 \\ ${ }^{2}$ The University of Queensland, UQ Centre for Clinical Research (UQCCR), Herston, QLD, Australia 4029 \\ ${ }^{3}$ Diamantina Institute, Princess Alexandra Hospital, The University of Queensland, Woolloongabba, QLD, Australia 4102 \\ ${ }^{4}$ Life Technologies, Austin, Texas 78744, USA
}

\begin{abstract}
MicroRNAs are noncoding regulators of gene expression, which act by repressing protein translation and/or degrading mRNA. Many have been shown to drive tumorigenesis in cancer, but functional studies to understand their mode of action are typically limited to single-target genes. In this study, we use synthetic biotinylated miRNA to pull down endogenous targets of miR-182-5p. We identified more than 1000 genes as potential targets of miR-182-5p, most of which have a known function in pathways underlying tumor biology. Specifically, functional enrichment analysis identified components of both the DNA damage response pathway and cell cycle to be highly represented in this target cohort. Experimental validation confirmed that miR-182-5p-mediated disruption of the homologous recombination (HR) pathway is a consequence of its ability to target multiple components in that pathway. Although there is a strong enrichment for the cell cycle ontology, we do not see primary proliferative defects as a consequence of miR-182-5p overexpression. We highlight targets that could be responsible for miR-182-5p-mediated disruption of other biological processes attributed in the literature so far. Finally, we show that miR182-5p is highly expressed in a panel of human breast cancer samples, highlighting its role as a potential oncomir in breast cancer.
\end{abstract}

Keywords: PARP inhibition; biotin pull-down; miRNA; target identification

\section{INTRODUCTION}

MicroRNAs (miRNAs) are short ( 22 nt), single-stranded, noncoding, negative regulators of gene expression in eukaryotes. An individual miRNA is capable of targeting hundreds of distinct mRNAs (Thomas et al. 2010), and together the $1150+$ human miRNAs are believed to modulate more than a third of the mRNA species encoded in the genome (Bartel 2009). miRNAs have been shown to be biologically significant in various cellular processes such as cell differentiation, proliferation, apoptosis, and development in humans as well as other model organisms (for review, see Kloosterman and Plasterk 2006). Thus, deregulation of miRNAs can result in abnormal growth and development leading to several disorders, including cancer.

Since the first study showing direct evidence of miR-17-92 acting as an oncogene in B-cell lymphomas (He et al. 2005),

${ }^{5}$ Present address: Wellcome Trust Centre for Human Genetics, University of Oxford, Oxford OX3 7BN, UK

${ }^{6}$ Corresponding authors

E-mail n.cloonan@genomicbiology.org

E-mail s.grimmond@uq.edu.au

Article published online ahead of print. Article and publication date are at http://www.rnajournal.org/cgi/doi/10.1261/rna.034926.112. the role of miRNAs as oncogenes or tumor suppressors has been reported in almost every type of cancer. In the case of breast cancer, miRNA expression profiling of more than 70 primary tumors and cell lines identified five miRNAs (miR-10b, miR125b, miR-145, miR-21, and miR-155) that were consistently deregulated (Iorio et al. 2005). miR-10b has subsequently been shown to play a role in the metastatic ability of breast cancer, positively regulating cell migration and invasion (Ma et al. 2007). miR-21, initially shown to be overexpressed in several human breast cancers (Iorio et al. 2005; Volinia et al. 2006), was later established to function as an oncogene ( $\mathrm{Si}$ et al. 2007) by targeting anti-metastatic genes TPM1 (Zhu et al. 2007), PDCD4 (Frankel et al. 2008), and Maspin (Zhu et al. 2008). These and other studies highlighted the importance of identifying miRNAs driving tumorigenesis and of accurate prediction followed by characterization of their biologically relevant targets. Intriguingly, some miRNAs (such as miR-17-5p) have been shown to have a dual role as both oncogenes and tumor suppressors, depending on the cellular model under investigation (He et al. 2005; Hossain et al. 2006; Volinia et al. 2006; Zhang et al. 2006), and this has been due to a combination of the gene networks targeted by the miRNA and the expression 
levels of target transcripts (Cloonan et al. 2008). These dualfunctioning miRNAs are of particular importance because they are key biological hubs that could be used to leverage a therapeutic outcome.

Another miRNA with this potential dual function is miR$182-5 \mathrm{p}$. This miRNA was first identified and cloned from the mouse eye (Lagos-Quintana et al. 2003) and has shown to be tumorigenic in melanoma (Segura et al. 2009) and endometrial cancer (Myatt et al. 2010) and is overexpressed in lung (Cho et al. 2009), prostate (Schaefer et al. 2010), and colon cancers (Sarver et al. 2009). It is also up-regulated in primary gliomas and is associated with poor prognosis for patients with metastasis (Jiang et al. 2010). In contrast, a tumor-suppressive role for miR-182-5p has been established in lung cancer (Sun et al. 2010; Zhang et al. 2011), and gastric adenocarcinoma (Kong et al. 2012), where overexpression of this miRNA leads to suppression of cell growth. Despite the widespread association of altered miR-182-5p expression across a range of human cancers, only a few targets have been identified so far; including FOXO3, MITF (Segura et al. 2009), FOXO1 (Guttilla and White 2009), BRCA1 (Moskwa et al. 2011), CTTN (Sun et al. 2010), RGS17 (Sun et al. 2010), and more recently CREB1 (Kong et al. 2012) and MTSS1 (Liu et al. 2012). Recently, miR-182-5p, along with other miRNAs in its cluster, has been shown to affect apoptosis, senescence, proliferation, and migration/motility in medulloblastoma (Weeraratne et al. 2012). We believe that a more thorough and systematic screen of miR-182-5p targets will help elucidate its biological role in tumor biology.

Accurate miRNA target gene prediction has been challenging due to several reasons, mostly the constantly evolving hypotheses surrounding the miRNA-mRNA target recognition principles. Initial studies showed miRNAs binding to the $3^{\prime}$ UTRs of their target mRNAs by partial complementation spanning 6-8 nt of the seed sequence in their $5^{\prime}$ end (Lim et al. 2005), and most computational target-prediction programs rely on evolutionary conservation of these seed sites to limit the high false-positive rates for such small sequence motifs (Brennecke et al. 2005; Krek et al. 2005; Lewis et al. 2005). Even with this limitation, there are typically hundreds to thousands of targets predicted for a single miRNA, and many are shown to be false positives when interrogated by luciferase assays (Bentwich 2005; Rajewsky 2006; Baek et al. 2008; Cloonan et al. 2008). Along with the lack of overlap between targets predicted by different programs (Saito and Saetrom 2010), this limits streamlined analysis of biologically relevant targets and their subsequent experimental validation.

Our study overcomes these obstacles by using a combination of biotinylated synthetic miRNA pull-downs (Cloonan et al. 2011) to capture endogenous mRNA targets of miR$182-5 \mathrm{p}$, and microarray expression profiling to identify them. We show that miR-182-5p targets more than 1000 genes including many well-characterized oncogenes and tumor suppressors. Its targets include multiple components of the BRCA1-dependent DNA damage response pathway and the downstream $G_{2}$ cell cycle checkpoint. In the context of breast cancer, we demonstrate that miR-182-5p's primary effect is to mediate the double-stranded DNA damage response. Finally, we observe overexpression of miR-182-5p in a panel of human breast cancer patient samples, establishing its role as a potential oncomir in human breast cancer.

\section{RESULTS}

\section{Identification of putative miR-182-5p targets using biotinylated pull-down method}

Endogenous targets of miR-182-5p in HEK293T cells were captured using biotinylated synthetic miRNAs as described in Cloonan et al. (2011). Transient transfections of biotinylated miR-182-5p molecules and mock transfections, to be used as negative controls in the subsequent analysis, were carried out simultaneously in the same cell line. Expression profiling was then performed on the pull-down fraction versus the mock-transfected samples using microarrays (Fig. 1A). The false discovery rate (FDR) was calculated to account for multiple testing (Benjamini and Hochberg 1995). Probes that met the 5\% FDR threshold (for one-sided tests) and with a fold-change $>1.25$ were considered significantly enriched in the pull-down (Fig. 1B). This differential expression analysis (see Materials and Methods) revealed 1235 probes (1091 genes) to be significantly enriched in the pulldown fractions (Supplemental Table 1).

Previously validated mRNA targets of miR-182-5p, BRCA1, RGS17, and FOXO3 were significantly enriched in our pull-down $(P$-values $\sim 0.005)$ (Fig. 1B), confirming the validity of our approach. Although there is no large-scale experimental validation of miR-182-5p targets with which to compare, we would expect to see an enrichment of predicted targets in our biotin pull-down data. To assess this, we compared the TargetScan (Lewis et al. 2005) predicted targets of miR-182-5p with our significantly enriched genes from the biotin pull-down (Fig. 1B,C). We observed an overlap of 113 genes, which was significantly more than we would predict by chance $\left(\chi^{2}\right.$ test; $P \approx 8 \times 10^{-24}$; degrees of freedom = 1 ), indicating that the biotin pull-down is enriched for predicted targets of miR-182-5p. Finally, we selected four previously uncharacterized targets (CDKN1B, CHEK2, SMARCD3, and NFKBIB), which also fall within our stringent significance threshold, and asked whether miR-182-5p could interact with these mRNAs. We cloned the predicted binding sites into the $3^{\prime}$ UTR of a luciferase reporter gene, and cotransfected either miR-182-5p mimic or a negative mimic control, and measured the luciferase activity $48 \mathrm{~h}$ post-transfection. Using this assay, we validated all four binding sites tested (Fig. 1B,D). Taken together, these results confirm that our pull-downs are enriching for genuine targets of miR-182-5p. 
A


D

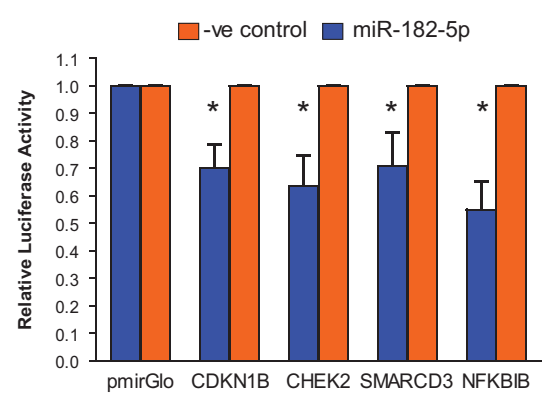

FIGURE 1. Identifying targets of miR-182-5p via biotin pull-down. (A) Hierarchical clustering of microarray data was performed using the plotSampleRelations function in the lumi package. Total vertical distance between samples indicates similarity. (B) A "volcano plot" showing the $\log _{2}$-transformed fold-change (mock/pull-down) versus the $\log _{10}$-transformed $P$-value for that fold-change for every gene detected above background in the microarray. (Blue) Genes that are targets validated by previous studies; (orange) genes predicted by TargetScan to be targets of miR-182-5p; (green) genes selected for validation using luciferase assays $(D)$. There is an apparent enrichment of the targets in the pull-downs compared with the controls. $(C)$ Venn diagram showing the overlap of genes between TargetScan-predicted targets of miR-182-5p (also expressed above background in HEK293Ts) and biotinylated miR-182-5p pull-down-predicted targets. This overlap is significantly more than expected by chance. $(D)$ Dual luciferase assay used to validate CHEK2, SMARCD3, CDKN1B, and NFKBIB as targets of miR-182-5p. HEK293T cells were transiently cotransfected with $20 \mathrm{nM}$ miR-182-5p or control mimic with a pmirGlo-luciferase construct containing the predicted binding site from the indicated target gene. Luciferase activity was normalized to Renilla activity; $\left(^{*}\right) P<0.05$ in a Student's $t$-test. The data plotted are the mean and SEM of three independent biological replicates.
miR-182-5p targets genes involved in the DNA damage response pathway

To infer the broad biological processes regulated by miR-182-5p, we performed gene set enrichment analysis (GSEA) on the full set of experimentally determined targets miR-182-5p (biotin pull-down) using Ingenuity Pathway Analysis (IPA, Ingenuity Systems). The enrichment of ontologies found in this set was compared with 10 randomly generated gene lists of equivalent size. Supplemental Table 2 lists all "Molecular and Cellular Functions" ( $P$-value $<0.002$ ), and Supplemental Table 3 lists all "Canonical Pathways" ( $P$-value $<0.02)$ associated with the miR-182$5 \mathrm{p}$-predicted targets where the $-\log (P-$ value) of the enrichment was at least one standard deviation away from the mean $-\log (P$-value $)$ from random gene lists. For all subsequent analysis and validations, we considered an ontology as significantly enriched if its $-\log (P$ value) was at least four standard deviations away from the mean of the $-\log$ $(P$-value) from the random gene sets (Cloonan et al. 2008).

Only two molecular processes were identified above our stringent threshold: "Gene Expression" (160 genes; $P$ value $\approx 1.15 \times 10^{-11}$ ), and "Cell Cycle" (114 genes; $P$-value $\approx 1.46 \times 10^{-10}$ ). Like many miRNAs, transcription factors are over-represented in miR-182$5 p$ targets (Cui et al. 2006). The cell cycle ontology is similarly broad, encompassing a variety of proliferative and regulatory functions from the direct control of proliferation to checkpoint control. Like others (Moskwa et al. 2011), we could not identify a proliferative defect in MDA-MB-231 cells upon inducing overexpression of miR-1825p (Fig. 2A,B). We constructed three independent cell lines that could overexpress miR-182-5p in response to doxycycline (Fig. 2A). Using all three stable cell lines, we examined the rate of proliferation (Fig. 2B) and the distribution of cells in each phase of the cell cycle (Fig. 2C), but were unable to detect any substantial differences. We 
A


E

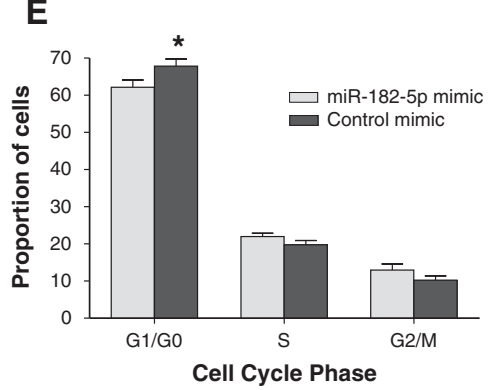

B

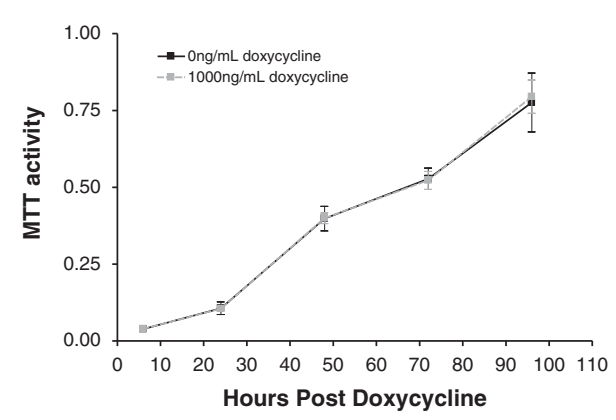

D

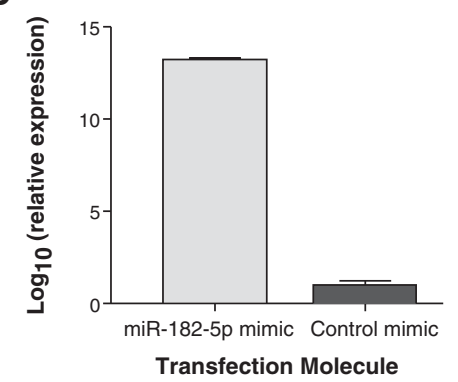

FIGURE 2. Overexpression of miR-182-5p does not induce a proliferative defect. $(A)$ Expression of miR-182-5p as assessed by qRT-PCR in MDA-MB-231 cells (with low endogenous expression of miR-182-5p) stably transfected with miR-182-5p whose expression is induced in response to doxycycline. Shown here are three independent cell lines grown in the presence of 0 or $1000 \mathrm{ng} /$ $\mathrm{mL}$ of doxycycline for $48 \mathrm{~h}$. RNU6B was used as an endogenous control for normalization of expression. (B) MTT cell proliferation assays of MDA-MB-231 cells stably expressing miR-182-5p. The graph plots the mean and SEM of the previously studied stable cell lines grown with either 0 or $1000 \mathrm{ng} / \mathrm{mL}$ doxycycline. The induction of miR-182-5p does not affect the proliferation rates of MDA-MB-231 cells. (C) DNA profile analysis of MDA-MB-231 cells stably expressing miR$182-5 \mathrm{p}$. The graph shows the mean and SEM of the percentage of cells in different cell cycle phases, as assessed by FACS. There was no significant difference between MDA-MB-231 cells expressing or not expressing miR-182-5p. (D) Expression of miR-182-5p in HeLa cells transiently transfected with miR-182-5p mimic or negative mimic control as assessed by qRT-PCR. RNU6B was used as an endogenous control for normalization of expression. (E) A graph showing the DNA profile analysis of HeLa cells transiently transfected with either miR-182-5p mimic or a control mimic. Shown is the mean and SEM of three independent biological replicates, each performed in technical triplicates. $\left({ }^{*}\right) P<0.05$ in a Student's $t$-test $(n=3)$.

were also unable to find a significant change in the proportion of cells in each phase of the cell cycle upon miR-182-5p overexpression in this system (Fig. 2C), and only a small (5\%) accumulation in the $\mathrm{G}_{1}$ phase of transiently transfected HeLa cells (Fig. 2D,E). Taken together, we conclude that miR$182-5 p$ is not sufficient to modulate proliferation or cell cycle progression in the cell lines tested here. However, this does not exclude a role for this miRNA in proliferation in other biological contexts or other aspects of cell cycle biology, such as checkpoint regulation.

We next sought to identify the canonical pathways enriched with predicted miR-182-5p targets. The most significantly enriched pathways were all facets of the DNA damage response (DDR) (Supplemental Table 3): "Cell Cycle: G2/M DNA Damage Checkpoint Regulation" ( $P$-value $\left.\approx 2.90 \times 10^{-05}\right)$, "Role of BRCA1 in DNA Damage Response" $\left(P\right.$-value $\left.\approx 8.50 \times 10^{-05}\right)$, "Hereditary Breast Cancer Signaling" ( $P$-value $\approx$ $\left.1.1 \times 10^{-04}\right)$, "Cyclins and Cell Cycle Regulation" $\left(P\right.$-value $\left.\approx 1.49 \times 10^{-04}\right)$, "Role of CHK Proteins in Cell Cycle Checkpoint Control" ( $P$-value $\approx 5.6 \times$ $\left.10^{-04}\right)$, and "ATM Signaling" ( $P$-value $\left.\approx 8.20 \times 10^{-04}\right)$. To confirm that this enrichment is not occurring in response to a foreign molecule being introduced into these cells, we transiently transfected $20 \mathrm{nM}$ miR-182-5p mimic $(\sim 3 \times$ the concentration of the biotinylated molecule) into MDA-MB-231 cells and evaluated expression levels of known DNA repair genes. Figure 3A shows that only ATF1 changed significantly between cells transfected with miR-182-5p or negative mimic control, but only to a small extent (1.16×). This confirms that there is no substantial and widespread DNA-damage response as a result of introducing an exogenous molecule into these cells. To further verify if this response is miR-182-5p specific, we performed functional enrichment analysis on biotin pull-down targets of other miRNAs (data generated in-house). Figure 3B shows the canonical pathway "Role of BRCA1 in DNA Damage Response" to be highly significant only in the miR-182-5p pull-down analysis. As shown in the figure, the level of enrichment in the miR-182-5p pull-down is at least four standard deviations away from the mean of $-\log$ (significance) of other miRNA pull-downs, suggesting that this enrichment is not occurring by chance and is a specific response to miR-182-5p overexpression.

DDR is a key pathway in cancer, and its disruption leads to genetic instability and promotes tumorigenesis (Deng 2006). 



FIGURE 3. Enrichment of targets in the DNA damage response is specific to miR-182-5p overexpression. (A) Real-time PCR analysis to evaluate the relative mRNA levels of known DNA repair genes was performed in MDA-MB-231 cells transiently transfected with $20 \mathrm{nM}$ miR-182-5p mimic or negative mimic. $\left(^{*}\right)$ Significant changes $(P<$ 0.05). Data were normalized using HPRT as the internal control. The results shown are from three independent biological replicates, each performed in technical quadruplicates. (B) Functional enrichment analysis was performed using biotin-enriched targets of several miRNAs including miR-182-5p. As shown, the canonical pathway "Role of BRCA1 in DNA Damage Response" is highly significant in the miR-182-5p pulldown with its $-\log$ (significance) at least four standard deviations away (top arrow) from the mean - $\log$ (significance) (lower arrow) of the other miRNAs. This confirms that the enrichment seen for targets in the DNA damage response is miR-182-5p specific and not occurring by chance.

Typically, this pathway is activated in response to doublestranded breaks (DSBs) leading to cell cycle arrest at either the p53-dependent $\mathrm{G}_{1} / \mathrm{S}$-phase checkpoint or the p53-independent $\mathrm{G}_{2} / \mathrm{M}$-phase DNA damage checkpoint (Moynahan et al. 1999; Moynahan and Jasin 2010), and regulates a specific set of gene products involved in DNA repair, such as BRCA1 (Khanna and Jackson 2001). Disruption to this pathway has been associated with a wide variety of malignancies including breast, ovarian, and pancreatic cancer (Lord and Ashworth 2012). Figure 4 shows an overview of this pathway and its downstream effects, with the pull-down-identified targets of miR-182-5p highlighted in dark gray. Of the 54 genes in this pathway, we have now identified $36(66.66 \%)$ as likely targets of miR-182-5p (Fig. 4; Supplemental Table 4).

A majority (32 of 36 ) of the miR-182-5p targets in this pathway are proteins that play a major role in the positive reg- ulation of the response to DNA damage, so their repression by miR-182-5p could lead to a disruption of the DDR pathway. There are, however, two classes of proteins that are an exception to this coherent model. First is the Cyclin-dependent Kinase 6 (CDK6), which, along with CDK4, is known to phosphorylate and inactivate $\mathrm{RB}$ (RB1), leading to the cell cycle progression (Meyerson and Harlow 1994). However, in response to DNA damage, this would typically lead to an accumulation of genomic instability and is therefore repressed by $\mathrm{p} 53$ (TP53), through p21 (CDKN1A) in vitro (see Fig. 4; Meyerson and Harlow 1994; Harper et al. 1995). Hence, repression of the CDKs by miR-182-5p would lead to activation of RB and a cell cycle arrest, enabling efficient DNA repair. The second class is the components of the SCF complex that are responsible for the ubiquitylation of several proteins that are essential for the DDR, e.g., SKP1 and 2, components of the SCF complex, which are known to degrade $\mathrm{p} 27^{\mathrm{KIP} 1}$ (CDKN1B), an essential mediator of cell cycle arrest in response to DNA damage (Cuadrado et al. 2009). Another component of the SCF complex, BTRC, is also known to ubiquitylate ATF4, which plays a role in maintaining genomic integrity (Lassot et al. 2001). The repression of these two classes of proteins by miR-182-5p could lead to a normal functioning DDR, which may explain the tumor-suppressive effects of this miRNA observed in lung cancer (Sun et al. 2010; Zhang et al. 2011), and human gastric adenocarcinoma (Kong et al. 2012), in a manner analogous to miR-17-5p's dual functionality (He et al. 2005; Hossain et al. 2006; Volinia et al. 2006; Zhang et al. 2006).

\section{miR-182-5p modulates PARP inhibitor sensitivity by targeting multiple components of the DNA repair pathway}

miR-182-5p has recently been reported to target BRCA1 (Moskwa et al. 2011), a critical component of the homologous recombination (HR) pathway, in breast cancer cell lines. Since it has been shown that some miRNAs concurrently target functionally related genes to drive a specific biological signal (Cloonan et al. 2008; Tsang et al. 2010; Ulitsky et al. 2010; Su et al. 2011) and miR-182-5p targets are enriched for genes involved in DNA damage repair, we hypothesized that miR182-5p's action on the HR pathway extends beyond the targeting of BRCA1. miR-182-5p targeting of CHEK2, an upstream regulator of BRCA1, should also alter sensitivity to the HR-mediated repair. Direct targeting of the predicted miR-182-5p-binding site in CHEK2 was confirmed by dual luciferase assay $(P<0.05)$ (Fig. 1D). We then used the BRCA1 wild-type MDA-MB-231 cells transiently transfected with miR-182-5p mimics in PARP inhibition assays, using different concentrations of ANI (PARP1 inhibitor 4-amino1,8 -naphthalimide) ranging from 0 to $10 \mu \mathrm{M}$. These cells were also shown to have an $\sim 1000$-fold increase in the expression of miR-182-5p relative to the negative control mimic in the MDA-MB-231 cells (Fig. 5B). PARP inhibitors are 


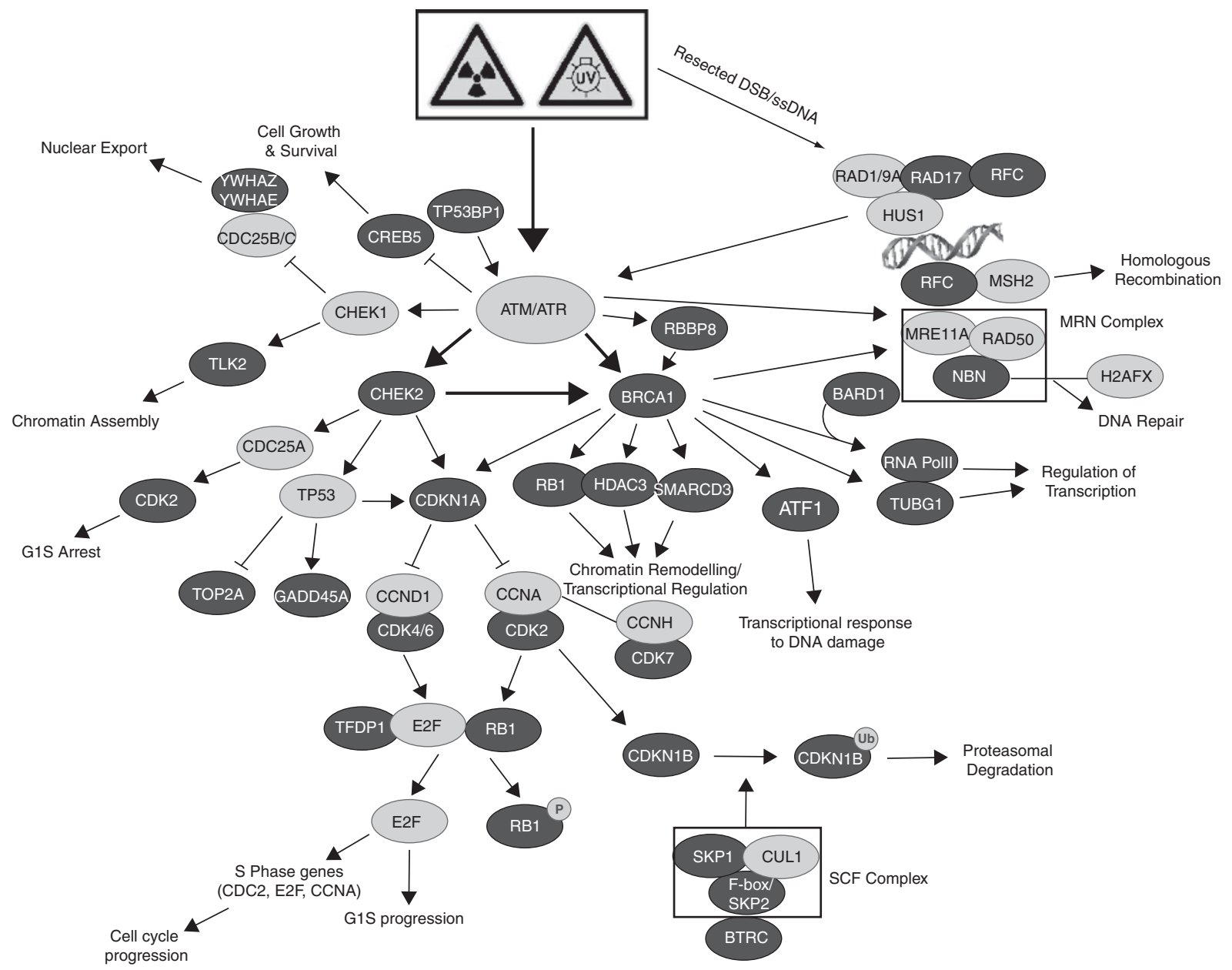

FIGURE 4. Overview of biotinylated miR-182-5p pull-down-predicted targets involved in the DNA damage response pathway genes involved in different canonical pathways underlying the DNA damage response, including the $\mathrm{G}_{2} \mathrm{M}$ cell cycle checkpoint, BRCA1-dependent HR-mediated pathway, cyclins and role of cell cycle regulators, role of CHK proteins, and ATM signaling. (Dark gray) miR-182-5p targets identified by biotin pull-down. These canonical pathways were found to be significantly enriched compared with 10 random gene lists of similar size using IPA $(P$-value $<0.02)$.

cytotoxic in cells deficient in HR-mediated repair, because the inhibitors suppress base excision repair (BER), which would normally compensate an HR deficiency. Increased sensitivity to PARP inhibitors would therefore indicate a reduction in HR function, and reintroduction of a miR-182-5p target ORF should rescue the phenotype (Fig. 5A).

As previously reported (Moskwa et al. 2011), overexpression of miR-182-5p sensitized the cells to PARP inhibition, as measured by clonogenic survival assays. We confirmed that reintroduction of the BRCA1 ORF could rescue this phenotype (Fig. 5C) with a $P$-value $<0.05$ at $0.01 \mu \mathrm{M}$ and $0.1 \mu \mathrm{M}$ showing 10\%-20\% increase in rescue of the cells. Our results also demonstrate that the phenotype can be rescued by CHEK2, where similar results were obtained with $20 \%-$ $30 \%$ increase in survival at the 0.1 and $1 \mu \mathrm{M}$ concentrations of the PARP inhibitor $(P$-value $<0.05)$, indicating that CHEK2 is another target of miR-182-5p that contributes to this phenotype.

\section{Validation of predicted binding sites in MDA-MB-231 cells}

Since the original target identification analysis was performed in the nonmalignant HEK293T cell lines, we sought to validate the interaction between miR-182-5p and some of the genes enriched in the biotin pull-down using MDA-MB231 breast cancer cells. We selected genes for which there was a single predicted binding site, for validation in luciferase assays. The predicted binding sites (and $\sim 60 \mathrm{nt}$ of surrounding sequence) were cloned into the $3^{\prime}$ UTR of the Dual Luciferase pmiRGlo vector and transiently transfected into cells. Luciferase activity, indicative of translation from the plasmid, was measured in the presence of miR-182-5p mimic or negative control mimic and normalized using Renilla activity. Using this approach, we were able to validate seven out of eight of the targets picked (87.5\%) (Fig. 6), including ATF1, RAD17, CHEK2, SMARD3, CREB5, TP53BP1, and 

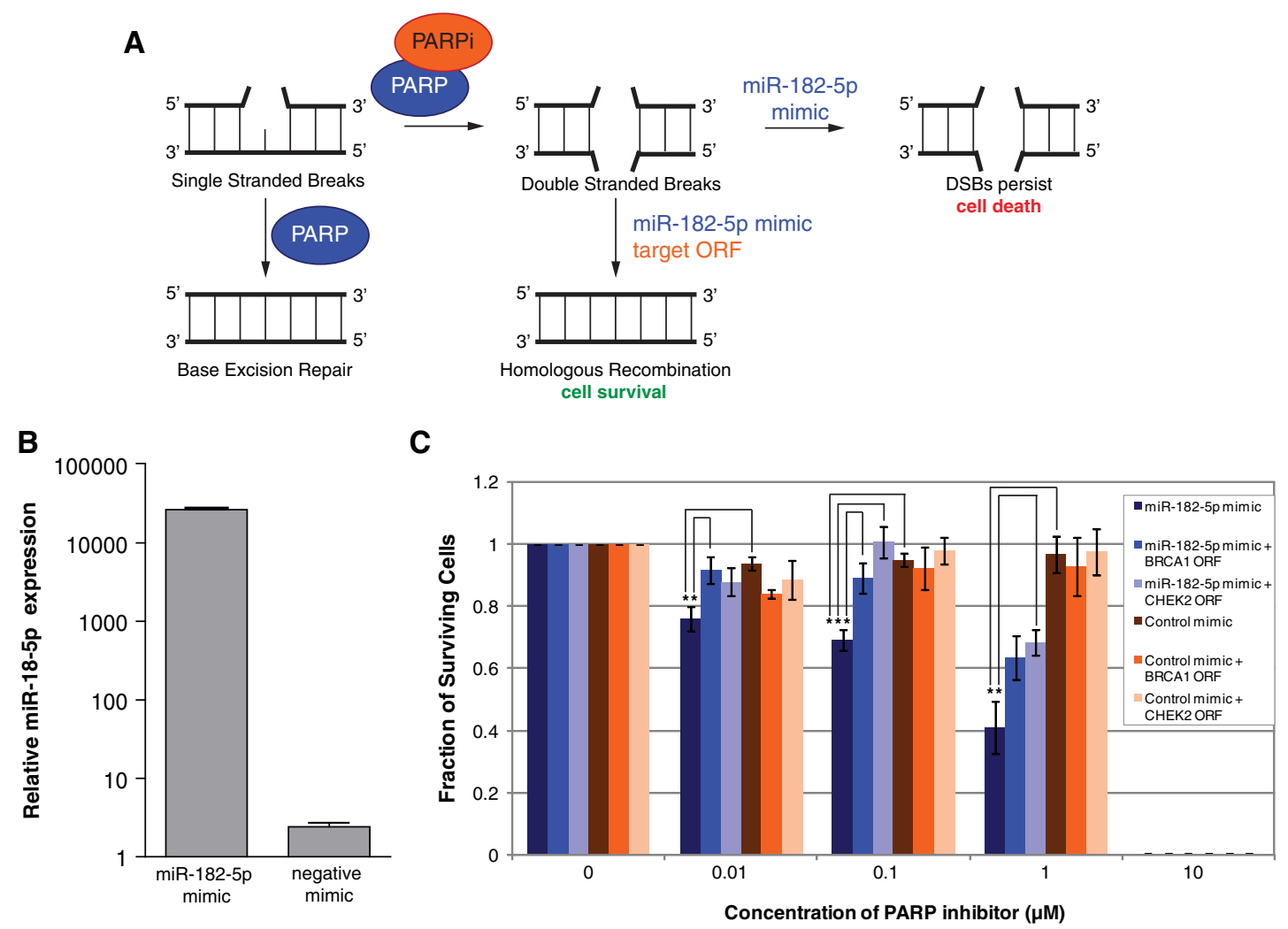

FIGURE 5. The effect of miR-182-5p on sensitivity to PARP inhibition in MDA-MB-231cells. (A) A schematic diagram depicting the principle of the PARP inhibitor assays performed here. Typically, cells with functional PARP repair single-strand breaks via the base excision repair pathway. In PARP inhibition assays, the inhibited PARP leads single-stranded breaks to decay to double-stranded breaks, which are then repaired via the homologous recombination (HR) pathway. However, in cells with a dysfunctional HR pathway (i.e., overexpressing miR-182-5p mimic leading to down-regulation of the DNA damage response [DDR] components), the DNA damage persists, leading to cell death. If a DDR target of an miR-182-5p target (e.g., $B R C A 1$ or $C H E K 2$ open reading frame [ORF]) is reintroduced, this would rescue any effect of miR-182-5p leading to increased cell survival. ( $B$ ) To assess the level of miR-182-5p overexpression, we performed real-time analysis in MDA-MB-231 cells transiently transfected with $10 \mathrm{nM}$ miR-182-5p or negative control mimic and find an $\sim 1000$-fold increase from the base level expression in these breast cancer cells. (C) BRCA1 and CHEK2 mediate sensitivity to PARP1 inhibitor, induced by overexpression of miR-182-5p. Cells were transiently transfected with miR-182-5p mimic or control mimic $( \pm \mathrm{ORF})$. Cell viability was assessed using the clonogenic survival assay in the presence of 4-amino-1,8-naphthalimide (ANI; PARP1 inhibitor) at the indicated concentrations on the $x$-axis. The data plotted are the mean and SEM of at least three independent biological replicates. $\left({ }^{*}\right) P<0.05$ in a Student's $t$-test.

CDKN1B. These data further strengthen our hypothesis that miR-182-5p targets the DNA repair pathway through a network of functionally related genes. Additionally, the high rate of validation seen here contrasts favorably with validation rates based on TargetScan predictions alone $(40 \%)$ (Cloonan et al. 2008), and confirms the ability of the biotin pull-down approach to enrich for genuine biological targets.

\section{miR-182-5p is frequently up-regulated in human breast cancer}

Although miR-182-5p has been shown to be important for development of breast cancer in cell lines and mice, no screens have been performed to determine its relevance to human breast cancer subtypes. We extended the analysis of miR182-5p expression to a cohort of human breast cancer patient samples (from the Brisbane Breast Bank, The University of
Queensland Centre for Clinical Research, UQCCR). The sample cohort $(n=40)$ included "Invasive Ductal CarcinomasNo Special Type" (IDC-NST) of different molecular subtypes including triple negative $(n=18) ; \mathrm{Her}^{+}(n=4), \mathrm{ER}^{+} / \mathrm{PR}^{+}(n$ $=9$ ); Invasive Lobular Carcinomas (ILC) $(n=3)$; and normal breast tissue $(n=6)$ (Supplemental Table 5). We included several molecular subtypes of breast cancer and assayed the expression levels of miR-182-5p relative to an endogenous control RNU6B, using qRT-PCR. As shown in Figure 7 (upper panel), miR-182-5p is highly expressed ( $\log _{10}$ fold-change [tumor/normal] $>1.5)$ in $32 / 40$ tumor samples $(\sim 80 \%)$ assayed relative to the normal controls, and all but one sample had higher expression in the tumors than any of the normal controls. The average expression of miR-182-5p in every tumor subtype is significantly higher $(P<0.0001)$ than the average expression across the normal breast tissue (Fig. 7, upper panel). Expression of miR-182-5p is highest across 


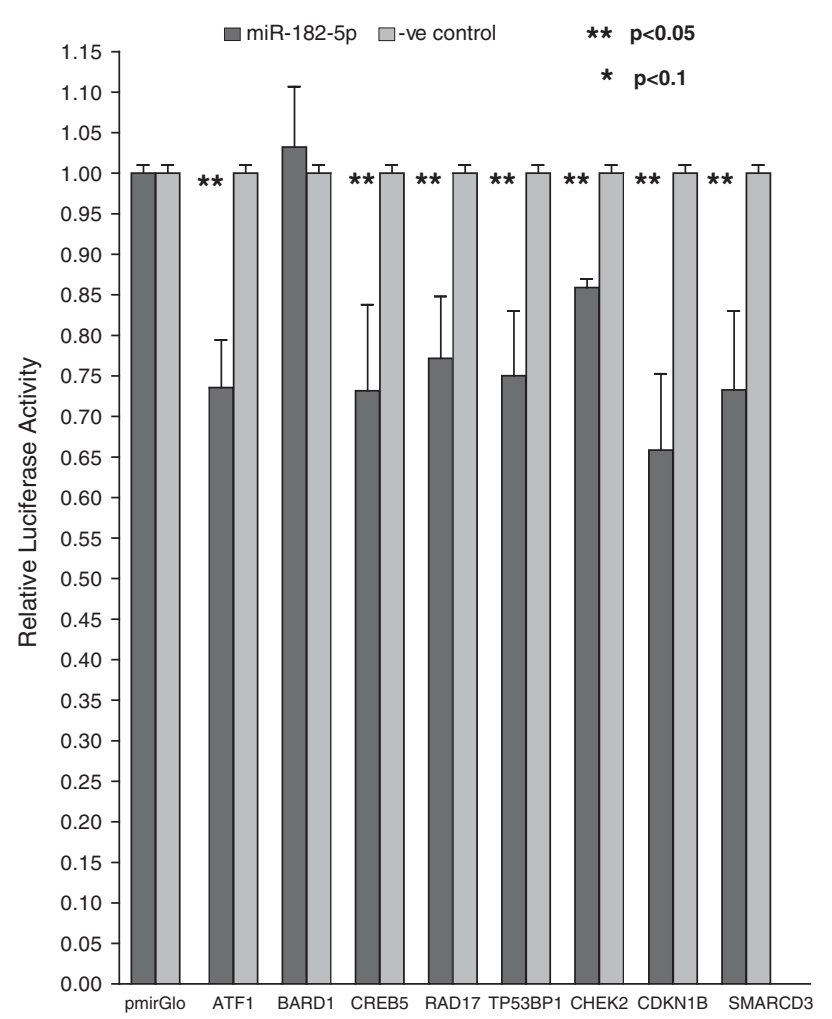

FIGURE 6. Dual luciferase assay used to validate targets of miR-182-5p. MDA-MB-231 cells were transiently cotransfected with $20 \mathrm{nM}$ miR182-5p or control mimic with a pmirGlo-luciferase construct containing the predicted binding site from the indicated target gene. Luciferase activity was normalized to Renilla activity; (**) $P<0.05$ as indicated in a Student's $t$-test. The data plotted are the mean and SEM of three independent biological replicates with three technical replicates.

the $\mathrm{ER}^{+} / \mathrm{PR}^{+}$luminal subtype; however, the expression of miR-182-5p is highly variable across the triple negative tumors, perhaps indicative of the heterogeneity within this class.

To confirm the relevance of miR-182-5p in an independent cohort of human breast cancers, we downloaded miRNA-seq data from the Cancer Genome Atlas (TCGA) data portal (https://tcga-data.nci.nih.gov/tcga/), which included both tumor $(n=741)$ and normal tissues $(n=99)$. The relative abundance of miRNAs was counted, and shown in Figure 7 (lower panel) is the reads per million of miR-182$5 \mathrm{p}$ across both the tumor and normal cohort, where we find a significant difference $(P<0.0001)$ in its level of expression. These results confirm that miR-182-5p is an important miRNA relevant to human cancer and that further study is warranted to clearly delineate its role in the pathogenesis and progression in specific breast cancer subtypes.

\section{DISCUSSION}

In this study, we have characterized transcriptome-wide mRNA targets of miR-182-5p using the affinity copurification of mRNA bound to biotin-labeled miRNAs (Cloonan et al. 2011). Gene set enrichment analysis (GSEA) of miR$182-5 p$ targets revealed that the DNA damage response was a core molecular pathway regulated by this miRNA. This pathway is critical in the normal functioning and replication of cells, and disruption can cause cellular transformation. PARP plays a key role in DNA repair via the base excision repair (BER) pathway. When PARP is inhibited, single-strand breaks (SSBs) degenerate to lethal DSBs, which, in the case of BRCA-negative cells or cells deficient in HR, leads to cell death (Bryant et al. 2005; McCabe et al. 2006). Importantly, we were able to partially rescue miR-182-5p-
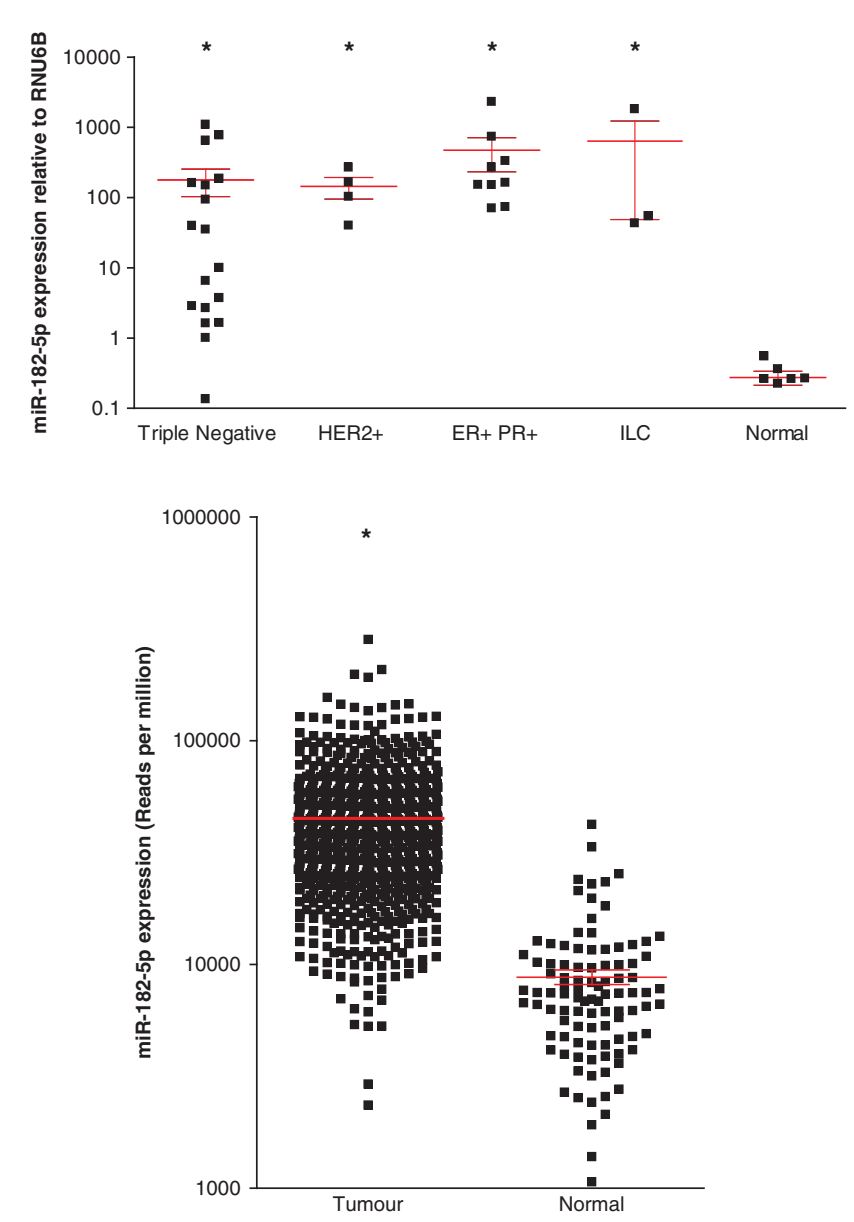

FIGURE 7. Expression analysis of miR-182-5p across tumor subtypes and normal tissue from human breast cancer patient samples. (Upper panel) Real-time PCR was performed in breast cancer patient samples of various subtypes to assess miR-182-5p expression, where lines and error bars represent the mean and SEM of miR-182-5p expression (normalized to RNU6B) across sample subtypes: Invasive Ductal Carcinoma of Triple Negative $(n-19)$; Her2 ${ }^{+}(n=4)$ or $\mathrm{ER}^{+} / \mathrm{PR}^{+}$ $(n=9)$ phenotype; Invasive Lobular Carcinomas $(n=3)$; and normal breast tissue $(n=6)$. ( $(-)$ Expression levels for individual patients; $\left(^{*}\right)$ indicate where the difference in the means subtype was $(P<0.0001)$ when compared with the normal samples. (Lower panel) Expression of miR182-5p across several breast cancer patient samples as assessed by miRNA-seq. Shown in the $x$-axis is reads per million of miR-182-5p in data downloaded from the TCGA web portal, which included tumors $(n=741)$ and normal tissue $(n=99) .(*)$ Where the difference in the means was $(P<0.0001)$ when compared with the normal samples. 
induced sensitivity to PARP inhibitors by restoring either BRCA1 or CHEK2 expression. Moskwa et al. (2011) previously concluded that BRCA1 was the key gene responsible for the miR-182-5p-induced sensitivity for PARP inhibitors, because $100 \%$ reversal of the sensitivity was observed upon reintroduction of BRCA1. However, the overexpression of BRCA1 under a strong promoter could easily compensate for the relatively weaker disruption to the pathway achieved by induction of an miRNA, and hence mask the contribution of other pathway members. Our results directly demonstrate that CHEK2 contributes to the miR-182-5p-induced sensitivity to PARP inhibition, but also suggest that other members of the pathway could contribute as well, confirmed by the luciferase assay validation in the breast cancer cells (Fig. 6). Together, repression of DNA damage repair could lead to genomic instability followed by cellular transformation (Fig. 8).

One of the well-studied consequences of suppressing the repair of DNA damage is the activation of apoptotic pathways, and this seems counterintuitive for a potential driver of tumorigenesis. There are two hypotheses that could explain this apparent contradiction. The first is that the combined effect of miR-182-5p targeting across a broad range of genes involved in DNA damage repair would manifest as a reduction in the fidelity of DNA repair, rather than a failure

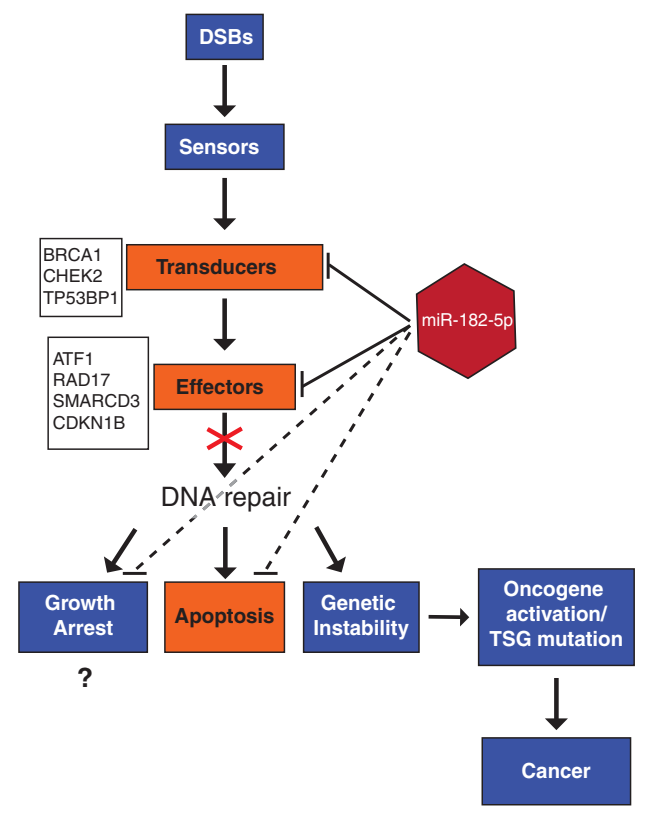

FIGURE 8. Model showing the effect of miR-182-5p on the DNA repair pathway. When a cell undergoes double-strand breaks (DSB), "sensor" genes activate a signaling cascade including transducer and effector genes that leads to an efficient repair of the DNA damage. Under this model, miR-182-5p-mediated deregulation of the DNA damage response pathway (orange) typically results in impaired DNA repair with subsequent effects on the cell cycle, apoptosis, or genetic stability leading to tumorigenesis. We have also highlighted previously validated and novel targets that we have mechanistically shown to interact with miR-182-5p, belonging to the DNA damage response pathway. of this pathway. This would increase the burden of mutation in these cells, possibly quite slowly, allowing the cells to accommodate and adapt to a modestly increasing mutation load. Such a hypothesis, while plausible, has not been directly tested in this study. The second (but not mutually exclusive) hypothesis is that miR-182-5p also directly suppresses the apoptotic pathway triggered by DNA damage. CDKN1B $\left(\mathrm{p} 27^{\mathrm{KIP} 1}\right.$ ) was a target of miR-182-5p identified by the biotin pull-down and validated using luciferase assay. This gene regulates $\mathrm{G}_{0}$-to-S phase transitions by interacting with cyclindependent kinases (CDKs) (Hengst and Reed 1998; Sherr and Roberts 1999), and overexpression of this gene has been shown to trigger apoptosis in the MDA-MB-231 cell line (Katayose et al. 1997) with pro-apoptotic properties in other cancers (Fujieda et al. 1999; Wu et al. 1999; Tenjo et al. 2000). Apoptosis has recently been identified as one of the deregulated pathways by the miR-182-5p cluster in medulloblastoma (Weeraratne et al. 2012), and suppression of $C D K N 1 B$ by miR-182-5p, along with other pro-apoptotic genes like $B A K$ and $B A X$ (Supplemental Table 1), suggests that apoptosis triggered by DNA damage could be deregulated by this miRNA.

Not all targets of miR-182-5p easily fit into the model proposed here (Fig. 8). Some targets-like BTRC, SKP1, SKP2, and the components of the SCF complex-are suppressors of DNA damage repair, and miR-182-5p suppression of these proteins would act to ensure genome fidelity. Relevant to this point are the conflicting reports regarding miR-182-5p's molecular role in tumorigenesis. Whereas there appears to be an oncogenic role for this miRNA in some cancers including melanoma (Segura et al. 2009), endometrioid endometrial cancer (Myatt et al. 2010), and glioma (Jiang et al. 2010); in others, such as lung adenocarcinoma (Sun et al. 2010; Zhang et al. 2011) and human gastric adenocarcinoma (Kong et al. 2012), its role is more akin to that of a tumor suppressor. Such dual-function miRNAs have been previously reported: miR-26a (Sander et al. 2008; Huse et al. 2009; Kota et al. 2009; Kim et al. 2010), miR-205 (Iorio et al. 2007, 2009; Gandellini et al. 2009; Wu et al. 2009), and miR-17-5p (Hossain et al. 2006; Mraz et al. 2009; Yu et al. 2010; Li et al. 2011) are all characterized examples. In the latter case, the molecular mechanism underlying the dual phenotype was uncovered through systematic screening of predicted targets through luciferase assays (Cloonan et al. 2008). Targeting both inhibitors and activators of DNA damage repair could either promote or inhibit genomic stability depending on the relative expression levels of those targets -and this could explain the conflicting reports of miR182-5p's role in tumorigenesis. For a firm conclusion to be made, independent validation of each target would be required. While the biotin pull-down has been optimized for high specificity, the presence of false-positive targets in the enrichment analysis should be considered while interpreting these results. Ongoing work suggests that the rate of false positives is $\leq 5 \%$ (data not shown), which would not be high 
enough to interfere with GSEA but may become critical when considering individual targets.

Many of the key genes involved in DNA repair also have annotated roles in the cell cycle, and GSEA correctly identified the cell cycle as an important molecular function of miR-182-5p targets. Although we found that ectopic expression of miR-182-5p was not sufficient to drive proliferation (confirming earlier reports) (Moskwa et al. 2011), we did observe minor cell cycle effects consistent with a DNA damage response. The HR-mediated repair is restricted to the $\mathrm{S}$ and $\mathrm{G}_{2}$ phases of the cell cycle (Moynahan et al. 1999; Moynahan and Jasin 2010) by several factors and detection of double-strand breaks would typically result in a $\mathrm{G}_{2}$ arrest. In our analysis with overexpression of miR-182-5p in HeLa cells (which would suppress this checkpoint), we see fewer cells in both the $S$ and $G_{2}$ phases with increased accumulation in the $G_{1}$ phase. This could be a result of a disrupted $G_{2}$ arrest as a result of the deregulated HR-mediated repair pathway (Fig. 8). Other studies have shown the miR-182-5p in conjunction with miR-96 and miR-27a (Guttilla and White 2009) can alter proliferation rates in MCF-7 breast cancer cells; hence, it could be that concomitant targeting of genes by all members of the miR-182-5p cluster and other mature miRNAs is essential to drive this phenotype.

We confirm the relevance of miR-182-5p dysregulation to human breast cancer by showing that this miRNA is overexpressed across a panel of human breast cancer samples, which belong to several molecular and pathological subtypes. Although overexpressed in the triple negative subtype, the variability of miR-182-5p expression within this subtype was substantially more than seen in any other classification. Triple negative tumors are typically characterized by BRCA deficiency and a disrupted HR pathway. Given miR-182-5p's role in HR-mediated DNA repair, it is possible that transcription factors that typically dysregulate protein components of this pathway are also dysregulating miR-182-5p transcription. In melanoma, miR-182-5p has been associated with the invasion/metastatic signaling cascade (Segura et al. 2009). We did not find a strong association between miR-182-5p and the metastatic lymph node status of samples, suggesting that its role in breast cancer is more likely tumorigenesis than tumor progression. However, further studies using matched primary and distant metastatic samples followed by functional validations are required to elucidate miR-182-5p's molecular role in each cancer subtype.

Of particular relevance to therapeutic biomarkers is miR182-5p's ability to induce sensitivity to PARP inhibitors through multiple effectors. This result could be of immense therapeutic value, potentially widening the opportunity to expand treatment from breast cancers with mutations in BRCA1/2 to tumors with miR-182-5p disrupted HR-mediated pathways. It is currently not clear what percentage of the sporadic breast tumor patients with a functional HR pathway would respond to treatment with PARP inhibitors. We have now shown miR-182-5p as a potential regulator of the HR- mediated DNA repair pathway, which is the major determinant of a cell's sensitivity to PARP inhibition. Further studies are required to address if the status of BRCA mutation and overexpression of miR-182-5p are mutually exclusive and if either one is sufficient to make cells PARP-inhibition sensitive. This could include nonbreast cancer tumors, such as ovarian cancer, where several sporadic cancer types display a "BRCA-like" phenotype (Turner et al. 2004). Intriguingly, overexpression of miR-182-5p has recently been shown to target BRCA1 in ovarian papillary serous carcinoma (Liu et al. 2012). An important subject of future studies would be to determine how well miR-182-5p performs as a prognostic or therapeutic biomarker.

\section{MATERIALS AND METHODS}

\section{Cell culture}

HEK293T, MDA-MB-231, and HeLa cells were maintained in DMEM (Life Technologies) with 10\% FBS and 1\% PenicillinStreptomycin (Life Technologies) and grown in a $5 \% \mathrm{CO}_{2}$ atmosphere at $37^{\circ} \mathrm{C}$. MDA-MB-231 and HeLa cell lines were purchased from Cell Bank; the HEK293T cell line was purchased from ATCC.

\section{Biotin pull-downs, microarray hybridizations, and analysis}

Pull-downs of miR-182-5p targets were carried out as previously described (Cloonan et al. 2011), using biotin-labeled oligonucleotides specific for miR-182-5p (Supplemental Table 6). Briefly, 50 pmol of biotin-labeled oligos (IDT) was transiently transfected into HEK293T cells and cultured for $24 \mathrm{~h}$. This was followed by cell lysis and binding of $50 \mu \mathrm{L}$ (Streptavidin), myOne C1 Dynabeads (Invitrogen) to the RNA fraction for enrichment. Fifty nanograms of captured mRNA fractions (three independent biological replicates) was amplified and labeled using the Illumina Total Prep RNA amplification kit (Ambion) as per the manufacturer's instructions. Samples were profiled on Illumina Human HT-12 chips along with control RNA from mock-transfected cells.

Microarray data were normalized using the lumi package (Du et al. 2008) by applying background adjustment, variance-stabilizing transformation (Lin et al. 2008), and robust spline normalization (Workman et al. 2002) successively. The lmFit and eBayes functions in the limma package (Smyth 2004) were used to test differential expression between the pull-down samples and the controls (Cloonan et al. 2011). The false discovery rate (FDR) was calculated to account for multiple testing (Benjamini and Hochberg 1995). Probes that met the 5\% FDR threshold (for one-sided tests) were considered significantly enriched in the pull-down. The transcripts (ENSEMBL V62) to which they matched exactly were considered putative targets of that miRNA. The targets enriched using the biotin pull-downs were analyzed using Ingenuity Pathway Analysis as previously described (Cloonan et al. 2008).

\section{Stable cell line generation}

MDA-MB-231 cells stably expressing miR-182-5p were generated using the Mir-X Inducible miRNA Systems (Clontech). Briefly, 
MDA-MB-231 cells were transfected with the pTet-on Advanced Vector using Lipofectamine 2000 (Life Technologies Australia, Invitrogen Division), and cells stably expressing the plasmid were selected using $800 \mu \mathrm{g} / \mathrm{mL}$ G418 (Life Technologies); maintenance concentration: $400 \mu \mathrm{g} / \mathrm{mL}$ G418. Primers (Supplemental Table 6) were used to amplify the miR-182-5p hairpin from human genomic DNA and cloned into the pmRI-ZsGreen I vector plasmid supplied and subsequently transfected into the 231-pTet-on parent line. Cells stably expressing pmRi-Zsgreen-miR-182-5p were selected using $1 \mu \mathrm{g} / \mathrm{mL}$ puromycin and further maintained in $0.5 \mu \mathrm{g} / \mathrm{mL}$ puromycin. Stable expression of miR-182-5p was confirmed using the miRNA Taqman Assay (Applied Biosystems) specific for miR182-5p (Fig. 2A).

\section{Clonogenic cell survival assay}

MDA-MB-231 cells were seeded overnight $\left(2 \times 10^{5}\right.$ cells/well in a 12 -well plate) and transfected with $10 \mathrm{nM}$ miRNA mimics (Ambion). In rescue experiments, miR-182-5p or control mimics were cotransfected with $0.5 \mu \mathrm{g}$ of BRCA1 or CHEK2 cDNA clones. After $48 \mathrm{~h}, 500$ cells in $2 \mathrm{~mL}$ of DMEM media (10\% FBS, v/v) were seeded on six-well plates in triplicate and incubated overnight before treatment. PARP inhibitors (4-amino-1, 8-naphthalimide [Sigma-Aldrich] in DMSO) were added to the growth media at 0 $\mu \mathrm{M}, 0.01 \mu \mathrm{M}, 0.1 \mu \mathrm{M}, 1 \mu \mathrm{M}$, and $10 \mu \mathrm{M}$ concentrations. Cells in the presence of PARP inhibitor were allowed to form colonies for $14 \mathrm{~d}$. For evaluation, formed colonies were stained with Crystal Violet and surviving colonies containing more than 50 cells were counted. The plating efficiency was $20 \%-35 \%$.

\section{Flow cytometry for cell cycle analysis}

HeLa cells were transiently transfected using $50 \mathrm{nM}$ miR-182-5p mirVana mimic (Life Technologies) using Lipofectamine 2000 (Invitrogen) as per the manufacturer's instructions. All cells were harvested and fixed in $70 \%$ ethanol overnight at $-20^{\circ} \mathrm{C}$. DNA was stained using $10 \mu \mathrm{g} / \mathrm{mL}$ propidium iodide (Sigma-Aldrich), and RNA was removed using $200 \mu \mathrm{g} / \mathrm{mL}$ RNase A (Sigma-Aldrich). Cells were filtered through a $35-\mu \mathrm{m}$ cell strainer mesh (BectonDickinson) and analyzed on Becton Dickinson LSR II flow cytometer fitted with a 488-nm laser. Cell data were gated and analyzed using FlowJo 7.2.2 (Tree Star, Inc.). The same fixing and FACS protocol was applied to MDA-MB-231 cells stably overexpressing miR-182-5p.

\section{Dual luciferase assay to validate predicted binding sites}

Predicted target sites of miR-182-5p were cloned into the Nhe1 and SalI sites of pmirGLO Dual-Luciferase miRNA Target Expression Vector (Promega). Synthetic oligos (Supplemental Table 6) corresponding to 60 nucleotides surrounding the target sequence were annealed before ligation into the pmirGlo plasmid. All constructs were verified by sequencing. HEK293T or MDA-MB-231 cells were cotransfected with $50 \mathrm{ng}$ of a pmirGlo construct and miR182-5p or negative mimic (Ambion) to a final concentration of $20 \mathrm{nM}$. Post-transfection, cells were incubated for $48 \mathrm{~h}$ prior to assaying. Luciferase activity was assayed using the Dual Luciferase Reporter Assay System (Promega) and detected on a Wallac 1420 luminometer (PerkinElmer). Luciferase activity was normalized to the internal control, Renilla activity in each well. Assays were conducted in triplicate and independently repeated three times.

\section{MTT proliferation assays}

Stable pmRi-MDA-MB-231 cell lines overexpressing miR-182-5p (1000 ng/mL doxycycline) and parent stables (with no doxycycline) were plated at $1 \times 10^{4}$ cells per well. MTT (3-[4,5-dimethylthiazol2-yl]-2,5-diphenyl tetrazolium bromide) activity was assayed using a Cell Growth Determination Kit (Sigma-Aldrich) according to the manufacturer's instructions and detected on a PowerWave XS spectrophotometer (BioTek).

\section{Clinical samples, RNA purification, and qRT-PCR analyses}

Human breast tumors were derived from the Brisbane Breast Bank, collected from consenting patients and with ethical approval from the research ethics committees of the Royal Brisbane \& Women's Hospital and the University of Queensland. Histological type, tumor grade, tumor size, lymph node status, and ER, PR, and HER2 status were obtained from the pathology reports. ER, PR, and HER2 biomarkers were used to infer molecular subtype as luminal, HER2, or triple negative. Total RNA from human tumor samples was extracted using tumor homogenization followed by TRIzol extraction (Invitrogen).

Total RNA was purified from cell lines using the miRNeasy Mini Kit (QIAGEN), and RNA integrity was assessed using an Agilent Bioanalyzer 2100. For mature miRNA, cDNA (5-10 ng of total RNA) was synthesized using a Taqman MicroRNA RT Kit (Applied Biosystems), and qRT-PCR was performed using a miR182-5p MicroRNA Taqman assay (Applied Biosystems). For mRNA expression analysis, $500 \mathrm{ng}$ of total RNA was reverse-transcribed using SuperScript III (Invitrogen), and a 1:50 dilution of the cDNA was used in the real-time PCR reaction. All RT-PCR was performed on an Applied Biosystems 7000 Sequence Detection System. For small RNA expression analysis, RNU6B was used as an endogenous control to normalize the data.

\section{DATA DEPOSITION}

The raw microarray data used in this study are available from the Gene Expression Omnibus (GEO) under accession number GSE38593.

\section{SUPPLEMENTAL MATERIAL}

Supplemental material is available for this article.

\section{ACKNOWLEDGMENTS}

This work was partially supported by Australian Research Council (ARC) Discovery Project Grant DP1093164. K.K. is supported by an Australian Post-graduate Award (APA); P.T.S. is supported by a fellowship from the National Breast Cancer Foundation, Australia; N.C. is supported by an ARC Postdoctoral Fellowship; and S.M.G. is supported by a National Health and Medical 
Research Council (NHMRC) Principal Research Fellowship. The Arrayed Retroviral Expression Cloning (ARVEC) facility kindly supplied the BRCA1 and CHEK2 ORFs. We are grateful for the helpful discussions with all members of QCMG, and we are particularly thankful to John Pearson, Darrin Taylor, and Scott Wood for HPC infrastructure and support.

Received June 13, 2012; accepted November 14, 2012.

\section{REFERENCES}

Baek D, Villen J, Shin C, Camargo FD, Gygi SP, Bartel DP. 2008. The impact of microRNAs on protein output. Nature 455: 64-71.

Bartel DP. 2009. MicroRNAs: Target recognition and regulatory functions. Cell 136: 215-233.

Benjamini Y, Hochberg Y. 1995. Controlling the false discovery rate: A practical and powerful approach to multiple testing. J R Stat Soc Series B Stat Methodol 57: 289-300.

Bentwich I. 2005. Prediction and validation of microRNAs and their targets. FEBS Lett 579: 5904-5910.

Brennecke J, Stark A, Russell RB, Cohen SM. 2005. Principles of microRNA-target recognition. PLoS Biol 3: e85. doi: 10.1371/ journal.pbio.0030085.

Bryant HE, Schultz N, Thomas HD, Parker KM, Flower D, Lopez E, Kyle S, Meuth M, Curtin NJ, Helleday T. 2005. Specific killing of BRCA2-deficient tumours with inhibitors of poly(ADP-ribose) polymerase. Nature 434: 913-917.

Cho WC, Chow AS, Au JS. 2009. Restoration of tumour suppressor hsa-miR-145 inhibits cancer cell growth in lung adenocarcinoma patients with epidermal growth factor receptor mutation. Eur J Cancer 45: 2197-2206.

Cloonan N, Brown MK, Steptoe AL, Wani S, Chan WL, Forrest AR, Kolle G, Gabrielli B, Grimmond SM. 2008. The miR-17-5p microRNA is a key regulator of the G1/S phase cell cycle transition. Genome Biol 9: R127. doi: 10.1186/gb-2008-9-8-r127.

Cloonan N, Wani S, Xu Q, Gu J, Lea K, Heater S, Barbacioru C, Steptoe AL, Martin HC, Nourbakhsh E, et al. 2011. MicroRNAs and their isomiRs function cooperatively to target common biological pathways. Genome Biol 12: R126. doi: 10.1186/gb-2011-12-12r126.

Cuadrado M, Gutierrez-Martinez P, Swat A, Nebreda AR, FernandezCapetillo O. 2009. p2 $7^{\mathrm{Kip} 1}$ stabilization is essential for the maintenance of cell cycle arrest in response to DNA damage. Cancer Res 69: 8726-8732.

Cui Q, Yu Z, Purisima EO, Wang E. 2006. Principles of microRNA regulation of a human cellular signaling network. Mol Syst Biol 2: 46. doi: $10.1038 / \mathrm{msb} 4100089$.

Deng CX. 2006. BRCA1: Cell cycle checkpoint, genetic instability, DNA damage response and cancer evolution. Nucleic Acids Res 34: $1416-1426$.

Du P, Kibbe WA, Lin SM. 2008. lumi: A pipeline for processing Illumina microarray. Bioinformatics 24: 1547-1548.

Frankel LB, Christoffersen NR, Jacobsen A, Lindow M, Krogh A, Lund AH. 2008. Programmed cell death 4 (PDCD4) is an important functional target of the microRNA miR-21 in breast cancer cells. $J$ Biol Chem 283: 1026-1033.

Fujieda S, Inuzuka M, Tanaka N, Sunaga H, Fan GK, Ito T, Sugimoto C, Tsuzuki H, Saito H. 1999. Expression of p27 is associated with Bax expression and spontaneous apoptosis in oral and oropharyngeal carcinoma. Int J Cancer 84: 315-320.

Gandellini P, Folini M, Longoni N, Pennati M, Binda M, Colecchia M, Salvioni R, Supino R, Moretti R, Limonta P, et al. 2009. miR-205 exerts tumor-suppressive functions in human prostate through downregulation of protein kinase Ce. Cancer Res 69: 2287-2295.

Guttilla IK, White BA. 2009. Coordinate regulation of FOXO1 by miR27a, miR-96, and miR-182 in breast cancer cells. J Biol Chem 284: 23204-23216.
Harper JW, Elledge SJ, Keyomarsi K, Dynlacht B, Tsai LH, Zhang P, Dobrowolski S, Bai C, Connell-Crowley L, Swindell E, et al. 1995. Inhibition of cyclin-dependent kinases by p21. Mol Biol Cell 6: 387-400.

He L, Thomson JM, Hemann MT, Hernando-Monge E, Mu D, Goodson S, Powers S, Cordon-Cardo C, Lowe SW, Hannon GJ, et al. 2005. A microRNA polycistron as a potential human oncogene. Nature 435: 828-833.

Hengst L, Reed SI. 1998. Inhibitors of the Cip/Kip family. Curr Top Microbiol Immunol 227: 25-41.

Hossain A, Kuo MT, Saunders GF. 2006. Mir-17-5p regulates breast cancer cell proliferation by inhibiting translation of AIB1 mRNA. Mol Cell Biol 26: 8191-8201.

Huse JT, Brennan C, Hambardzumyan D, Wee B, Pena J, Rouhanifard SH, Sohn-Lee C, le Sage C, Agami R, Tuschl T, et al. 2009. The PTEN-regulating microRNA miR-26a is amplified in high-grade glioma and facilitates gliomagenesis in vivo. Genes Dev 23: 1327-1337.

Iorio MV, Ferracin M, Liu CG, Veronese A, Spizzo R, Sabbioni S, Magri E, Pedriali M, Fabbri M, Campiglio M, et al. 2005. MicroRNA gene expression deregulation in human breast cancer. Cancer Res 65: 7065-7070.

Iorio MV, Visone R, Di Leva G, Donati V, Petrocca F, Casalini P, Taccioli C, Volinia S, Liu CG, Alder H, et al. 2007. MicroRNA signatures in human ovarian cancer. Cancer Res 67: 8699-8707.

Iorio MV, Casalini P, Piovan C, Di Leva G, Merlo A, Triulzi T, Ménard S, Croce CM, Tagliabue E. 2009. microRNA-205 regulates HER3 in human breast cancer. Cancer Res 69: 2195-2200.

Jiang L, Mao P, Song L, Wu J, Huang J, Lin C, Yuan J, Qu L, Cheng SY, Li J. 2010. miR-182 as a prognostic marker for glioma progression and patient survival. Am J Pathol 177: 29-38.

Katayose Y, Kim M, Rakkar AN, Li Z, Cowan KH, Seth P. 1997. Promoting apoptosis: A novel activity associated with the cyclin-dependent kinase inhibitor p27. Cancer Res 57: 5441-5445.

Khanna KK, Jackson SP. 2001. DNA double-strand breaks: Signaling, repair and the cancer connection. Nat Genet 27: 247-254.

Kim H, Huang W, Jiang X, Pennicooke B, Park PJ, Johnson MD. 2010. Integrative genome analysis reveals an oncomir/oncogene cluster regulating glioblastoma survivorship. Proc Natl Acad Sci 107: 2183-2188.

Kloosterman WP, Plasterk RH. 2006. The diverse functions of microRNAs in animal development and disease. Dev Cell 11: 441-450.

Kong WQ, Bai R, Liu T, Cai CL, Liu M, Li X, Tang H. 2012. MicroRNA182 targets cyclic adenosine monophosphate responsive element binding protein 1 (CREB1) and suppresses cell growth in human gastric adenocarcinoma. FEBS J 279: 1252-1260.

Kota J, Chivukula RR, O’Donnell KA, Wentzel EA, Montgomery CL, Hwang HW, Chang TC, Vivekanandan P, Torbenson M, Clark KR, et al. 2009. Therapeutic microRNA delivery suppresses tumorigenesis in a murine liver cancer model. Cell 137: 1005-1017.

Krek A, Grün D, Poy MN, Wolf R, Rosenberg L, Epstein EJ, MacMenamin P, da Piedade I, Gunsalus KC, Stoffel M, et al. 2005. Combinatorial microRNA target predictions. Nat Genet 37: 495-500.

Lagos-Quintana M, Rauhut R, Meyer J, Borkhardt A, Tuschl T. 2003. New microRNAs from mouse and human. RNA 9: 175-179.

Lassot I, Ségéral E, Berlioz-Torrent C, Durand H, Groussin L, Hai T, Benarous R, Margottin-Goguet F. 2001. ATF4 degradation relies on a phosphorylation-dependent interaction with the $\mathrm{SCF}^{\beta \operatorname{TrCP}}$ ubiquitin ligase. Mol Cell Biol 21: 2192-2202.

Lewis BP, Burge CB, Bartel DP. 2005. Conserved seed pairing, often flanked by adenosines, indicates that thousands of human genes are microRNA targets. Cell 120: 15-20.

Li H, Bian C, Liao L, Li J, Zhao RC. 2011. miR-17-5p promotes human breast cancer cell migration and invasion through suppression of HBP1. Breast Cancer Res Treat 126: 565-575.

Lim LP, Lau NC, Garrett-Engele P, Grimson A, Schelter JM, Castle J, Bartel DP, Linsley PS, Johnson JM. 2005. Microarray analysis shows that some microRNAs downregulate large numbers of target mRNAs. Nature 433: 769-773. 
Lin SM, Du P, Huber W, Kibbe WA. 2008. Model-based variance-stabilizing transformation for Illumina microarray data. Nucleic Acids Res 36: e11. doi: 10.1093/nar/gkm1075.

Liu Z, Liu J, Segura MF, Shao C, Lee P, Gong Y, Hernando E, Wei JJ. 2012. MiR182 overexpression in tumorigenesis of high-grade ovarian papillary serous carcinoma. J Pathol 228: 204-215.

Lord CJ, Ashworth A. 2012. The DNA damage response and cancer therapy. Nature 481: 287-294.

Ma L, Teruya-Feldstein J, Weinberg RA. 2007. Tumour invasion and metastasis initiated by microRNA-10b in breast cancer. Nature 449: 682-688.

McCabe N, Turner NC, Lord CJ, Kluzek K, Bialkowska A, Swift S, Giavara S, O'Connor MJ, Tutt AN, Zdzienicka MZ, et al. 2006. Deficiency in the repair of DNA damage by homologous recombination and sensitivity to poly(ADP-ribose) polymerase inhibition. Cancer Res 66: 8109-8115.

Meyerson M, Harlow E. 1994. Identification of G1 kinase activity for cdk6, a novel cyclin D partner. Mol Cell Biol 14: 2077-2086.

Moskwa P, Buffa FM, Pan Y, Panchakshari R, Gottipati P, Muschel RJ, Beech J, Kulshrestha R, Abdelmohsen K, Weinstock DM, et al. 2011. miR-182-mediated downregulation of BRCA1 impacts DNA repair and sensitivity to PARP inhibitors. Mol Cell 41: 210-220.

Moynahan ME, Jasin M. 2010. Mitotic homologous recombination maintains genomic stability and suppresses tumorigenesis. Nat Rev Mol Cell Biol 11: 196-207.

Moynahan ME, Chiu JW, Koller BH, Jasin M. 1999. Brcal controls homology-directed DNA repair. Mol Cell 4: 511-518.

Mraz M, Malinova K, Kotaskova J, Pavlova S, Tichy B, Malcikova J, Stano Kozubik K, Smardova J, Brychtova Y, Doubek M, et al. 2009. miR-34a, miR-29c and miR-17-5p are downregulated in CLL patients with TP53 abnormalities. Leukemia 23: $1159-1163$.

Myatt SS, Wang J, Monteiro LJ, Christian M, Ho KK, Fusi L, Dina RE, Brosens JJ, Ghaem-Maghami S, Lam EW. 2010. Definition of microRNAs that repress expression of the tumor suppressor gene FOXO1 in endometrial cancer. Cancer Res 70: 367-377.

Rajewsky N. 2006. microRNA target predictions in animals. Nat Genet 38: S8-S13.

Saito T, Saetrom P. 2010. MicroRNAs—-targeting and target prediction. N Biotechnol 27: 243-249.

Sander S, Bullinger L, Klapproth K, Fiedler K, Kestler HA, Barth TF, Möller P, Stilgenbauer S, Pollack JR, Wirth T. 2008. MYC stimulates $\mathrm{EZH} 2$ expression by repression of its negative regulator miR-26a. Blood 112: 4202-4212.

Sarver AL, French AJ, Borralho PM, Thayanithy V, Oberg AL, Silverstein KA, Morlan BW, Riska SM, Boardman LA, Cunningham JM, et al. 2009. Human colon cancer profiles show differential microRNA expression depending on mismatch repair status and are characteristic of undifferentiated proliferative states. $B M C$ Cancer 9: 401. doi: 10.1186/1471-2407-9-401.

Schaefer A, Jung M, Mollenkopf HJ, Wagner I, Stephan C, Jentzmik F, Miller K, Lein M, Kristiansen G, Jung K. 2010. Diagnostic and prognostic implications of microRNA profiling in prostate carcinoma. Int J Cancer 126: 1166-1176.

Segura MF, Hanniford D, Menendez S, Reavie L, Zou X, Alvarez-Diaz S, Zakrzewski J, Blochin E, Rose A, Bogunovic D, et al. 2009. Aberrant miR-182 expression promotes melanoma metastasis by repressing FOXO3 and microphthalmia-associated transcription factor. Proc Natl Acad Sci 106: 1814-1819.

Sherr CJ, Roberts JM. 1999. CDK inhibitors: Positive and negative regulators of $\mathrm{G}_{1}$-phase progression. Genes Dev 13: 1501-1512.
Si ML, Zhu S, Wu H, Lu Z, Wu F, Mo YY. 2007. miR-21-mediated tumor growth. Oncogene 26: 2799-2803.

Smyth GK. 2004. Linear models and empirical Bayes methods for assessing differential expression in microarray experiments. Stat Appl Genet Mol Biol 3: Article3. doi: 10.2202/1544-6115.1027.

Su WL, Kleinhanz RR, Schadt EE. 2011. Characterizing the role of miRNAs within gene regulatory networks using integrative genomics techniques. Mol Syst Biol 7: 490. doi: 10.1038/msb.2011.23.

Sun Y, Fang R, Li C, Li L, Li F, Ye X, Chen H. 2010. Hsa-mir-182 suppresses lung tumorigenesis through down regulation of RGS17 expression in vitro. Biochem Biophys Res Commun 396: 501-507.

Tenjo T, Toyoda M, Okuda J, Watanabe I, Yamamoto T, Tanaka K, Ohtani M, Nohara T, Kawasaki H, Tanigawa N. 2000. Prognostic significance of $\mathrm{p} 27^{\mathrm{kip} 1}$ protein expression and spontaneous apoptosis in patients with colorectal adenocarcinomas. Oncology 58: 45-51.

Thomas M, Lieberman J, Lal A. 2010. Desperately seeking microRNA targets. Nat Struct Mol Biol 17: 1169-1174.

Tsang JS, Ebert MS, van Oudenaarden A. 2010. Genome-wide dissection of microRNA functions and cotargeting networks using gene set signatures. Mol Cell 38: 140-153.

Turner N, Tutt A, Ashworth A. 2004. Hallmarks of 'BRCAness' in sporadic cancers. Nat Rev Cancer 4: 814-819.

Ulitsky I, Laurent LC, Shamir R. 2010. Towards computational prediction of microRNA function and activity. Nucleic Acids Res 38: e160. doi: 10.1093/nar/gkq570.

Volinia S, Calin GA, Liu CG, Ambs S, Cimmino A, Petrocca F, Visone R, Iorio M, Roldo C, Ferracin M, et al. 2006. A microRNA expression signature of human solid tumors defines cancer gene targets. Proc Natl Acad Sci 103: 2257-2261.

Weeraratne SD, Amani V, Teider N, Pierre-Francois J, Winter D, Kye MJ, Sengupta S, Archer T, Remke M, Bai AH, et al. 2012. Pleiotropic effects of miR-183 96 182 converge to regulate cell survival, proliferation and migration in medulloblastoma. Acta Neuropathol 123: 539-552.

Workman C, Jensen LJ, Jarmer H, Berka R, Gautier L, Nielser HB, Saxild HH, Nielsen C, Brunak S, Knudsen S. 2002. A new non-linear normalization method for reducing variability in DNA microarray experiments. Genome Biol 3: presearch0048-research0048.16.

Wu J, Shen ZZ, Lu JS, Jiang M, Han QX, Fontana JA, Barsky SH, Shao ZM. 1999. Prognostic role of $\mathrm{p} 27^{\mathrm{Kip} 1}$ and apoptosis in human breast cancer. Br J Cancer 79: 1572-1578.

Wu H, Zhu S, Mo YY. 2009. Suppression of cell growth and invasion by miR-205 in breast cancer. Cell Res 19: 439-448.

Yu J, Ohuchida K, Mizumoto K, Fujita H, Nakata K, Tanaka M. 2010. MicroRNA miR-17-5p is overexpressed in pancreatic cancer, associated with a poor prognosis, and involved in cancer cell proliferation and invasion. Cancer Biol Ther 10: 748-757.

Zhang L, Huang J, Yang N, Greshock J, Megraw MS, Giannakakis A, Liang S, Naylor TL, Barchetti A, Ward MR, et al. 2006. microRNAs exhibit high frequency genomic alterations in human cancer. Proc Natl Acad Sci 103: 9136-9141.

Zhang L, Liu T, Huang Y, Liu J. 2011. microRNA-182 inhibits the proliferation and invasion of human lung adenocarcinoma cells through its effect on human cortical actin-associated protein. Int J Mol Med 28: $381-388$.

Zhu S, Si ML, Wu H, Mo YY. 2007. MicroRNA-21 targets the tumor suppressor gene tropomyosin 1 (TPM1). J Biol Chem 282: 1432814336.

Zhu S, Wu H, Wu F, Nie D, Sheng S, Mo YY. 2008. MicroRNA-21 targets tumor suppressor genes in invasion and metastasis. Cell Res 18: 350-359. 

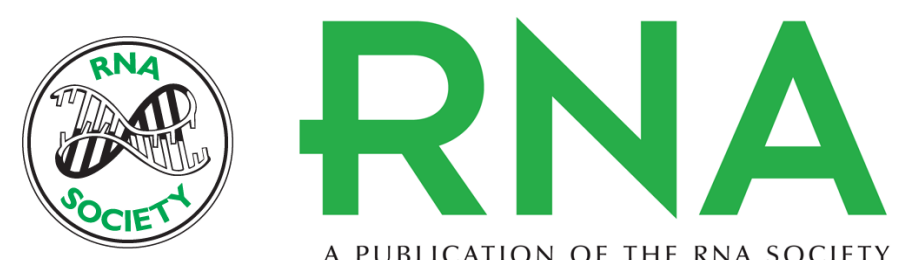

A PUBLICATION OF THE RNA SOCIETY

\section{MicroRNA-182-5p targets a network of genes involved in DNA repair}

Keerthana Krishnan, Anita L. Steptoe, Hilary C. Martin, et al.

RNA 2013 19: 230-242 originally published online December 18, 2012

Access the most recent version at doi:10.1261/rna.034926.112

Supplemental Material

References

Open Access

License Freely available online through the RNA Open Access option.

Freely available online through the RNA Open Access option.
http://rnajournal.cshlp.org/content/suppl/2012/12/05/rna.034926.112.DC1

This article cites 75 articles, 24 of which can be accessed free at: http://rnajournal.cshlp.org/content/19/2/230.full.html\#ref-list-1

Receive free email alerts when new articles cite this article - sign up in the box at the top right corner of the article or click here. 